\title{
Blocks to thyroid cancer cell apoptosis can be overcome by inhibition of the MAPK and PI3K/AKT pathways
}

\author{
V Gunda ${ }^{1}$, O Bucur ${ }^{2,3}$, J Varnau ${ }^{4}$, P Vanden Borre ${ }^{1}$, MJ Bernasconi ${ }^{1}$, R Khosravi-Far ${ }^{2}$ and S Parangi ${ }^{\star 1}$
}

Current treatment for recurrent and aggressive/anaplastic thyroid cancers is ineffective. Novel targeted therapies aimed at the inhibition of the mutated oncoprotein $\mathrm{BRAF}^{\mathrm{V} 600 \mathrm{E}}$ have shown promise in vivo and in vitro but do not result in cellular apoptosis. TNF-related apoptosis-inducing ligand (TRAIL) induces apoptosis in a tumor-selective manner by activating the extrinsic apoptotic pathway. Here, we show that a TRAIL-R2 agonist antibody, lexatumumab, induces apoptosis effectively in some thyroid cancer cell lines (HTh-7, TPC-1 and BCPAP), while more aggressive anaplastic cell lines (8505c and SW1736) show resistance. Treatment of the most resistant cell line, $8505 \mathrm{c}$, using lexatumumab in combination with the $\mathrm{BRAF}^{\mathrm{V} 600 \mathrm{E}}$ inhibitor, PLX4720, and the PI3K inhibitor, LY294002, (triple-drug combination) sensitizes the cells by triggering both the extrinsic and intrinsic apoptotic pathways in vitro as well as $8505 \mathrm{c}$ orthotopic thyroid tumors in vivo. A decrease in anti-apoptotic proteins, pAkt, Bcl-xL, Mcl-1 and c-FLIP, coupled with an increase in the activator proteins, Bax and Bim, results in an increase in the Bax to $\mathrm{Bcl}-\mathrm{xL}$ ratio that appears to be critical for sensitization and subsequent apoptosis of these resistant cells. Our results suggest that targeting the death receptor pathway in thyroid cancer can be a promising strategy for inducing apoptosis in thyroid cancer cells, although combination with other kinase inhibitors may be needed in some of the more aggressive tumors initially resistant to apoptosis.

Cell Death and Disease (2014) 5, e1104; doi:10.1038/cddis.2014.78; published online 6 March 2014

Subject Category: Cancer

The incidence of well-differentiated thyroid cancers in United States has increased dramatically in the past decade. ${ }^{1}$ Patients with the most common type of thyroid cancer, papillary thyroid cancer (PTC), have a low risk of recurrence and high survival. However, a subset of patients with anaplastic thyroid cancer (ATC) present with large invasive tumors and/or metastases, do not respond to any chemotherapeutic regimen and often die within months. ${ }^{2}$ New data are emerging on the genetic or epigenetic changes, which seem to contribute to such dramatic worsening of the prognosis in ATC compared with most other thyroid cancers. ${ }^{3}$ Correlative studies have pointed to increased incidence of mortality in patients who have activating BRAF ${ }^{\mathrm{V} 600 \mathrm{E}}$ mutations $^{4-6}$ in the mitogen-activated protein kinase (MAPK)/extracellular signalregulated kinase (ERK) signaling pathway. ${ }^{7,8}$ Therapeutics blocking this signaling pathway are currently in clinical trials. ${ }^{9}$ Although BRAF ${ }^{\mathrm{V} 600 \mathrm{E}}$ inhibitors work well in vitro in an antiproliferative and anti-invasive capacity and effectively reduce tumor volume in vivo in animal models, they are not capable of inducing apoptosis in thyroid cancer cells. ${ }^{10-12}$ Little is known regarding the mechanisms underlying resistance to apoptosis in these thyroid cancer cells. Here, we looked at using novel apoptotic agents to increase thyroid tumor apoptosis by activating the death receptor pathway and showed that in some cases combination with anti-BRAF therapies is necessary to fully activate apoptosis.

TNF-related apoptosis-inducing ligand (TRAIL) ligand is a promising agent that induces apoptosis in a tumor-specific manner by interacting with specific death domain receptors, TRAIL-R1 (DR4) and TRAIL-R2 (DR5). Activation of death domain receptors induces formation of the intracellular cytoplasmic Death-Inducing Signaling Complex (DISC), which directly activates the extrinsic apoptotic pathway while also crosstalking with the intrinsic pathway through Bid. ${ }^{13,14}$ Lexatumumab (HGS-ETR2) is a fully humanized agonistic monoclonal antibody that specifically activates the TRAIL-R2 and has never been tested in thyroid cancer in any capacity. Lexatumumab is currently in phase $\mathrm{I} / \mathrm{II}$ trials in advanced malignancy. This antibody approach has several advantages over the TRAIL ligand itself including improved pharmacokinetics and lack of decoy receptor binding, ${ }^{15-17}$ although some tumors exhibit resistance to apoptosis. ${ }^{18}$ Resistance

\footnotetext{
${ }^{1}$ Thyroid Cancer Research Laboratory, Unit of Endocrine Surgery Unit, Harvard Medical School, Massachusetts General Hospital, Boston, MA, USA; ${ }^{2}$ Department of Pathology, Harvard Medical School and Beth Israel Deaconess Medical Center, Boston, MA, USA; ${ }^{3}$ Department of Molecular Cell Biology, Institute of Biochemistry of the Romanian Academy, Bucharest, Romania and ${ }^{4}$ Indiana University School of Medicine, Indianapolis, IN, USA

${ }^{*}$ Corresponding author: S Parangi, Thyroid Cancer Research Laboratory, Unit of Endocrine Surgery Unit, Harvard Medical School, Massachusetts General Hospital, Wang ACC 460, 15 Parkman Street, Boston, MA 02115, USA. Tel: +1 617643 4806; Fax: +1 617643 4802; E-mail: sparangi@ partners.org Keywords: apoptosis; thyroid cancer; BRAF ${ }^{\mathrm{V} 600 \mathrm{E}}$ inhibitor; orthotropic; TRAIL

Abbreviations: TRAIL, TNF-related apoptosis-inducing ligand; PTC, Papillary thyroid cancer; ATC, Anaplastic thyroid cancer; MAPK, Mitogen-activated protein kinase; ERK, Extracellular signal-regulated kinase; PI3K, Phosphoinositide 3-kinase; DISC, Death Inducing Signaling Complex; c-FLIP, c-FLICE-like inhibitory protein; IAP, Inhibitors of apoptosis; TUNEL, Terminal deoxynucleotidyl transferase-mediated dUTP nick end labeling; TGl, Tumor growth inhibition

Received 04.11.13; revised 23.1.14; accepted 24.1.14; Edited by A Stephanou
} 
mechanisms include activation of c-FLICE-like inhibitory protein (c-FLIP), ${ }^{19,20}$ reduced expression of TRAIL-R2 and TRAIL-R1 receptors on tumor cell surface, overexpression of anti-apoptotic proteins (Bcl-2, Bcl-xL and inhibitors of apoptosis (IAP) family members) and reduced expression of proapoptotic proteins (Bax). Low Bax/Bcl-xL ratio has also been shown to have a critical role in TRAIL resistance. ${ }^{21-23}$ Lexatumumab has been combined with various drugs to overcome resistance to apoptosis in a variety of tumors in vitro and in vivo. These have included small molecule inhibitors (lapatanib, ${ }^{24}$ cycloheximide ${ }^{25}$ ), chemotherapeutic agents (cisplatin, ${ }^{26}$ dacarbazine ${ }^{27}$ ), antiangiogenic factors $\left(3 \mathrm{TSR}^{18}\right)$ and also PI3K and MAPK inhibitors. ${ }^{28-31}$ However, no studies of apoptosis with lexatumumab have been performed in thyroid cancer.

\section{Results}

Some thyroid cancer cell lines showed exquisite sensitivity to lexatumumab-induced apoptosis. Treatment with lexatumumab $(1000 \mathrm{ng} / \mathrm{ml})$ for $24 \mathrm{~h}$ resulted in significant apoptosis in three of the five thyroid cancer cell lines. Apoptosis was measured by annexinV/PE staining for the percent of annexinV-positive cells. The cell lines TPC-1 (98.6.1 $\pm 1.0 \%, P<0.001)$, HTh-7 (82.9 $\pm 15.5 \%, P<0.001)$ and BCPAP $(82.6 \pm 22.3 \%, P<0.01)$ showed dramatically higher percentage of apoptosis than the positive control, colon cancer cell line HCT116 ${ }^{18}(38.9 \pm 4.6 \%, P<0.01$; Figure 1a). TPC-1 was the most sensitive to lexatumumab with an IC50 of $\sim 194 \mathrm{ng} / \mathrm{ml}$ followed by HTh-7 ( 220.4 ng/ml) and BCPAP ( 401.5 ng/ml; Figure 1b). Lexatumumab-induced apoptosis was confirmed in all three sensitive cell lines by TUNEL staining, cleavage of caspases-8/-9, the effector caspase-3 and PARP, thus demonstrating activation of both extrinsic and intrinsic pathways. c-FLIP, the inhibitor of caspase-8, decreased with lexatumumab treatment (Figures $1 \mathrm{c}$ and $\mathrm{d}$ ). All cell lines had functionally active TRAIL-R2 receptors, with the highest levels present in these sensitive cell lines (Figure $3 \mathrm{c}$ ). At $8 \mathrm{~h}$ there was a decrease in the TRAIL-R2 surface receptor after lexatumumab treatment, perhaps due to the high rate of cell death. Normal thyroid cells, HTori, did not undergo apoptosis with lexatumumab treatment (Figure 1a).

Lexatumumab inhibits BCPAP tumor growth in an orthotropic mouse model. To evaluate whether the dramatic effect of lexatumumab observed in vitro would also result in tumor volume reductions in vivo, we examined the efficacy of lexatumumab in mice bearing orthotopically implanted BCPAP tumors. The BCPAP cell line was chosen for in vivo testing because previous experiments in our laboratory have shown that the other sensitive cell lines (TPC-1, HTh-7) do not grow well in mice (unpublished data). As previously described, ${ }^{32}$ BCPAP cells were implanted into the left thyroid lobe of SCID mice. Three weeks post implantation when the tumor volume ranged from $\sim 30$ to $40 \mathrm{~mm}^{3}$, treatment was started twice weekly for 4 weeks total. Six of the mice were treated with intravenous (IV) injections of lexatumumab antibody (10 mg/kg body weight) and six with saline (Figure 2a). Four weeks of lexatumumab treatment significantly reduced tumor volume from $204 \pm 42.5$ to $66.5 \pm 26.7 \mathrm{~mm}^{3}, \quad(P<0.001)$, with a TGI of $67.4 \%$ (Figure $2 \mathrm{~b}$ ). Lexatumumab-treated tumors were TTF1-positive and showed significantly higher percentage of apoptotic cells by TUNEL and cleaved caspse-3 staining compared with controls $(14.59 \pm 2.16 \%$ versus $2.47 \pm 0.6 \%$, $P<0.001$; Figure 2c). Of note, there are no lung metastases in this BCPAP orthotopic model. ${ }^{33}$

Some thyroid cancer cell lines were completely resistant to lexatumumab-induced apoptosis, whereas others showed intermediate sensitivity. $8505 \mathrm{c}$ cells were completely resistant to lexatumumab-induced apoptosis $(4.9 \pm 0.9 \%)$ even at $1000 \mathrm{ng} / \mathrm{ml}$ (Figure 3a), and there was no caspase cascade activation and no apoptotic cells on TUNEL staining (Supplementary Figure S1). One other ATC cell line, SW1736 (BRAF $^{\mathrm{V} 600 \mathrm{E}}$ ) showed reduced sensitivity to lexatumumabinduced apoptosis $(23.7 \%$ cell death, $P<0.05)$ with some intermediate activation of the extrinsic and intrinsic pathway caspases (Figure 4a). Given a high background in annexinV-PE staining in the SW1736 cell line, the MTS assay was used for determining cell viability in this particular cell line (Figure $3 b$ ).

Baseline expression of pro- and anti- apoptotic proteins was different among sensitive and resistant thyroid cancer cell lines and was altered with lexatumumab treatment. The baseline expression of pro- and anti-apoptotic proteins was analyzed in detail. Generally in the cell lines that responded with high or intermediate rates of apoptosis to the lexatumumab (HTh7, TPC-1, BCPAP and SW1736), the baseline expression of the pro-apoptotic protein, Bax, was high resulting in a high $\mathrm{Bax}$ to $\mathrm{Bcl}-\mathrm{xL}$ ratio. The resistant $8505 \mathrm{c}$ cells, however, expressed low Bax and high Bcl-xL protein levels, resulting in a low $\mathrm{Bax} / \mathrm{Bcl}-\mathrm{xL}$ ratio (Figure $3 \mathrm{c}$ ).

The two sensitive cell lines, HTh7 and TPC-1, had high baseline pAkt levels, which rapidly went down with lexatumumab treatment (result not shown), whereas the two cell lines, 8505c and SW1736, had with high pAkt level that increased further with lexatumumab treatment (Figures $3 a$ and b). BCPAP had low levels of pAkt that remained low even after lexatumumab treatment.

\footnotetext{
Figure 1 Lexatumumab induced apoptosis in various thyroid cancer cell lines. (a) TPC-1, BCPAP, HTh-7 and 8505c human thyroid cancer cell lines were treated with lexatumumab $(1000 \mathrm{ng} / \mathrm{ml})$ for $24 \mathrm{~h}$. The apoptotic cell population was assayed by annexinV-PE staining and represented as mean \pm S.D. of three individual experiments. Three cell lines were highly sensitive to lexatumumab-induced cell death versus untreated control, TPC-1 (98.6.1 $\pm 1.0 \%, P<0.001), H$ Th-7 (82.9 $\pm 15.5 \%, P<0.001)$ and $\operatorname{BCPAP}(82.6 \pm 22.3 \%, P<0.01)$. HCT116, a colon cancer cell line, was used as a positive control and had a $38.9 \pm 9.2 \%, P<0.01$ apoptotic response. $8505 \mathrm{c}$ ATC cells were completely resistant to apoptosis $(4.9 \pm 0.9 \%, P>0.05)$. (b) IC50 values for lexatumumab were determined using MTS assay for each cell line; TPC-1 was the most sensitive at $194 \mathrm{ng} / \mathrm{ml}$, HTh-7 $(220.4 \mathrm{ng} / \mathrm{ml})$ and BCPAP $(401.5 \mathrm{ng} / \mathrm{ml})$. (c) Phase-contrast microscopy showed that lexatumumab treated TPC-1, BCPAP and HTh-7 cells had a rounded/apoptotic morphology and were positive for TUNEL staining. (d) TPC-1, BCPAP and HTh-7 cells treated with lexatumumab (100 ng/ml and $1000 \mathrm{ng} / \mathrm{ml})$ for $8 \mathrm{~h}$ showed caspase 8, 9, 3 and PARP cleavage. cFLIP and TRAIL-R2 decreased in the lexatumumab treatment groups in all the three cell lines. $\beta$-actin was used for loading control. $\left({ }^{* *} P<0.001\right.$ versus control)
} 
a
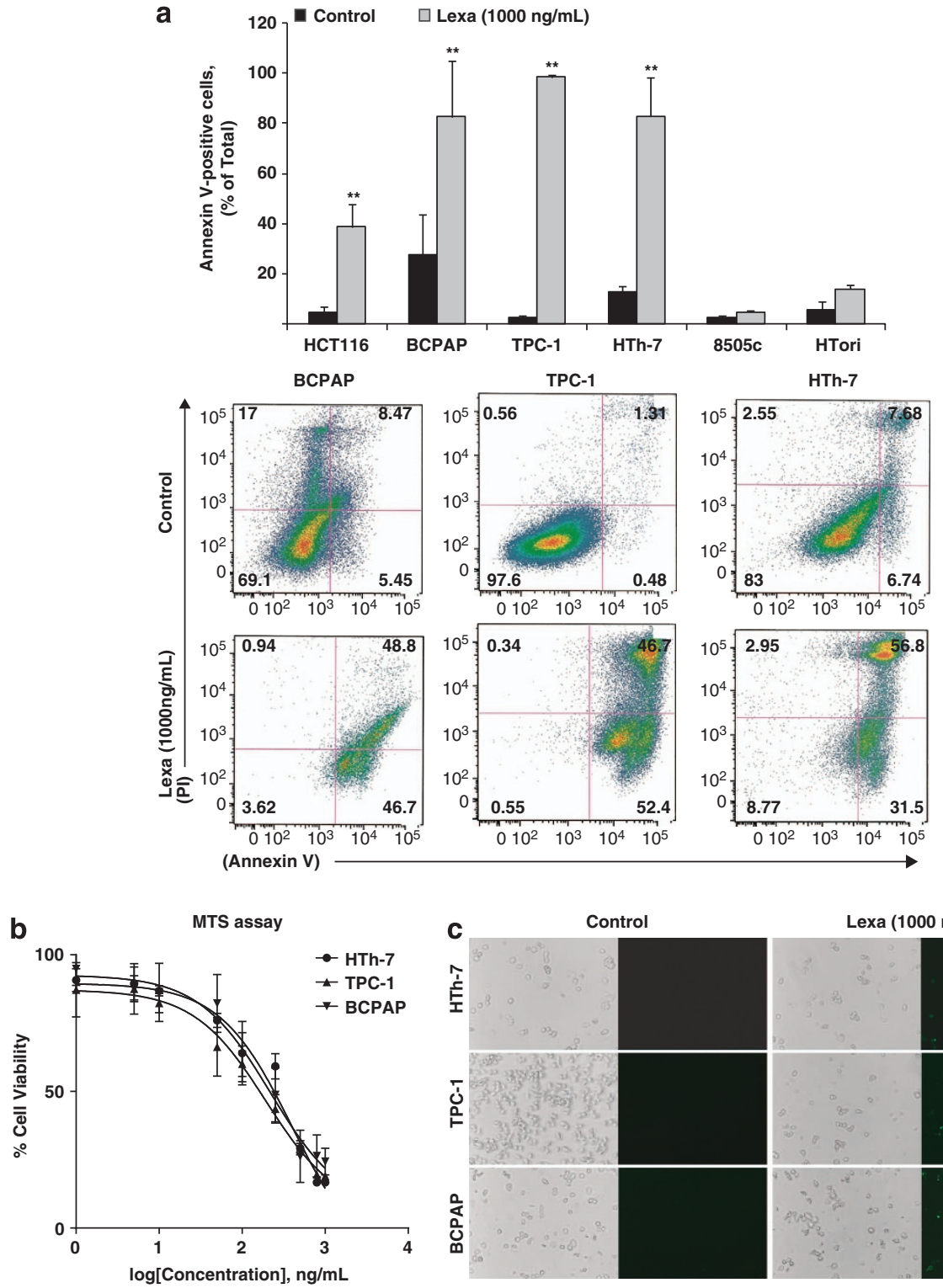

Lexa $(1000 \mathrm{ng} / \mathrm{mL})$

d

BCPAP TPC-1 HTh-7

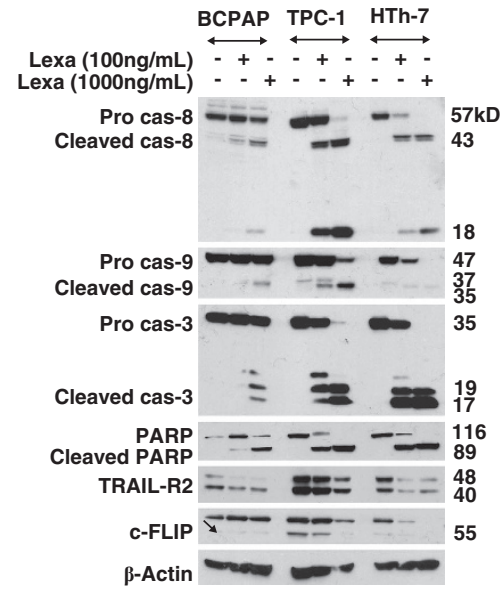

$(x)$ Informative band 
a
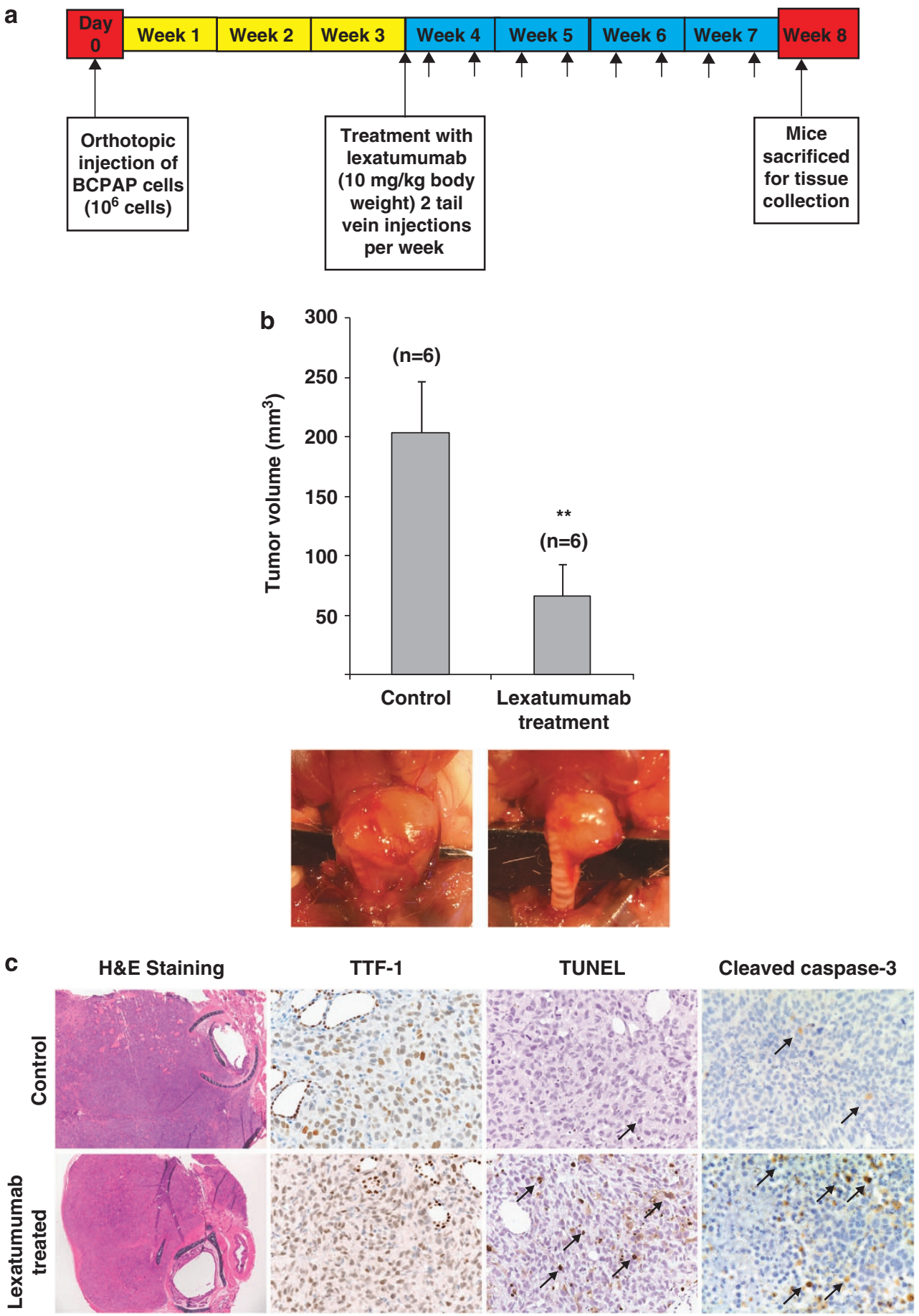

Figure 2 Lexatumumab inhibited tumor growth in a BCPAP orthotopic thyroid cancer model. One million BCPAP human papillary thyroid cancer cells were implanted into the left thyroid of the SCID mouse. (a) Three weeks post implantation, mice $(n=6)$ were injected twice weekly with lexatumumab ( $10 \mathrm{mg} / \mathrm{kg}$ body weight) I.V. or saline $(n=6)$ for 4 weeks. (b) Lexatumumab treatment resulted in a $67.4 \%$ reduction in tumor growth when compared with control $\left(204 \pm 42.5\right.$ to $\left.66.5 \pm 26.7 \mathrm{~mm}^{3}, P<0.001\right)$. (c) Orthotopic tumors treated with lexatumumab showed less aggressive histology on H\&E but maintained strong staining for TTF-1 and showed significantly higher percentage of apoptotic cells by TUNEL $(14.59 \pm 2.16 \%$ versus $2.47 \pm 0.6 \%, P<0.001)$ and cleaved caspse- 3 staining, compared with controls. A representative of the cells undergoing apoptosis (TUNEL-positive cells and cells showing cleaved caspase) was indicated by the arrows in the figure. $\left({ }^{* *} P<0.001\right.$ versus control)

High pAkt levels contribute to resistance to apoptosis in the SW1736 cell line with intermediate sensitivity to lexatumumab, and apoptosis can be enhanced by inhibition of the PI3K pathway. Given the importance of pAkt in contributing to TRAIL resistance in other malignancies, ${ }^{30,34}$ we hypothesized that the high baseline pAkt and the further increased levels with lexatumumab treatment contributed to the SW1736 cells' intermediate sensitivity to this drug. While lexatumumab alone triggered a $23 \%$ cell death rate, addition of the PI3K/pAkt inhibitor, 
a

$$
\text { 位 }
$$

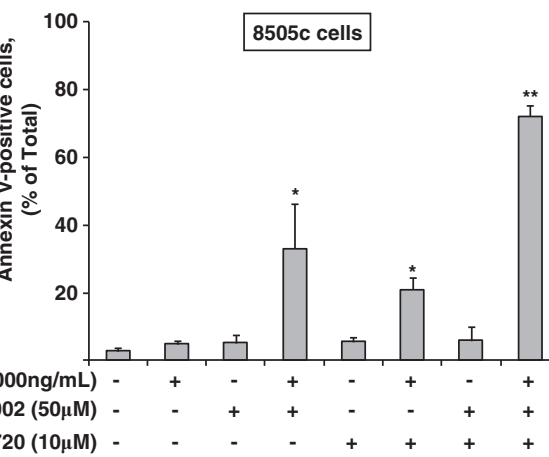

PLX4720 (10 $\mu \mathrm{M})$ -

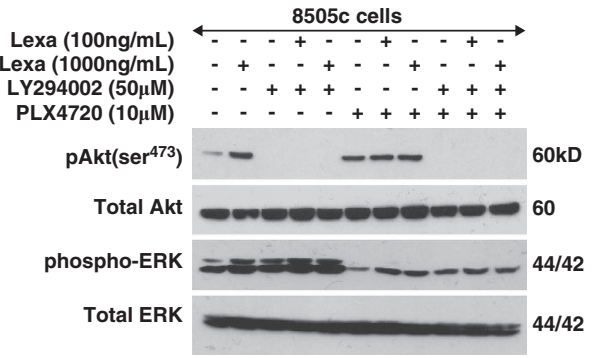

b

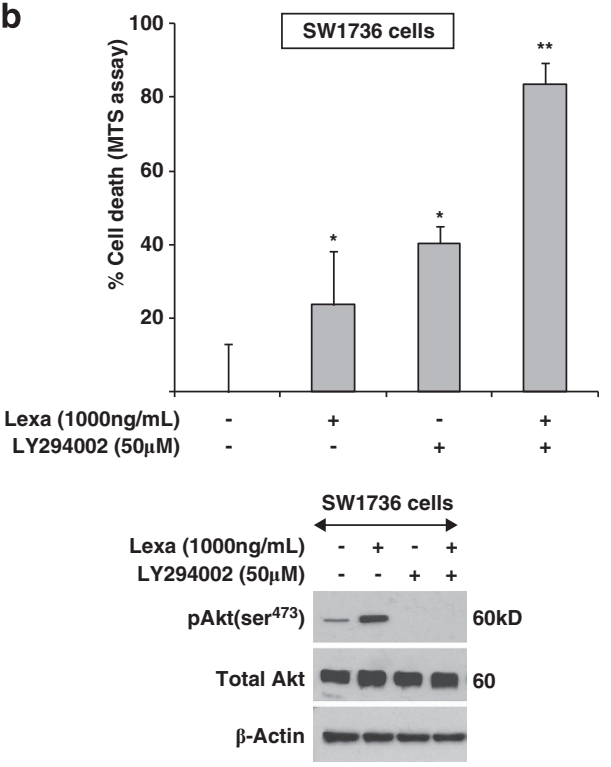

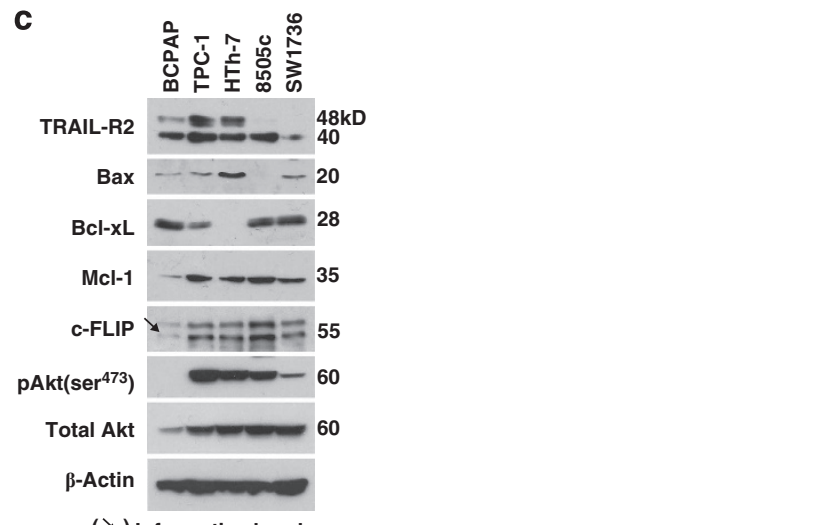

( $)$ Informative band

Figure 3 Further inhibition of the PI3K and MAPK pathways sensitized ATC cell lines, 8505c (BRAF ${ }^{\mathrm{V} 600 \mathrm{E} /}$-) and SW1736 (BRAF $\mathrm{B}^{\mathrm{V} 600 \mathrm{E} / \mathrm{wt}}$ ) to lexatumumab induced apoptosis. 8505c and SW1736 ATC cells were treated with lexatumumab, LY294002, PLX4720 either alone or in combination as indicated in the Figure for $48 \mathrm{~h}$. At the end of the treatment, the percentage of cells undergoing apoptosis were assessed using annexinV-PE staining in $8505 \mathrm{c}$ cells $(n=3)$, whereas the percentages of dead cells were determined using MTS assay for SW1736 cells $(n=3)$. (a) In the resistant $8505 \mathrm{c}$ cells, no single agent induced a significant apoptosis. Treatment with the combination of LY294002 $(50 \mu \mathrm{M})$ and lexatumumab $(1000 \mathrm{ng} / \mathrm{ml})$ resulted in a significant apoptotic cell death $(33.1 \pm 13.2 \%, P<0.01$ versus control). However, the three drug combination of lexatumumab, LY294002 and PLX4720 was most effective with an apoptotic cell population of $72.1 \pm 3.2 \%(P<0.001$ versus control). Western blot at $8 \mathrm{~h}$ of treatment showed the effective inhibition of pAkt and phospho-ERK by LY294002 and PLX4720, respectively. (b) Treatment of the intermediately sensitive SW1736 cells with the combination of $\mathrm{LY} 294002(50 \mu \mathrm{M})$ and lexatumumab $(1000 \mathrm{ng} / \mathrm{ml})$ resulted in a very effective cell death at $83.7 \pm 5.6 \%, P<0.001$. Western blot showed the effective inhibition of pAkt by LY294002. (c) Comparison of baseline expression of various pro- and anti-apoptotic proteins showed that the resistant 8505 cells had a low Bax to Bcl-xL ratio compared with the other lexatumumab-sensitive thyroid cell lines (BCPAP, TPC-1 and HTh7). ( ${ }^{\star} P<0.01$ and ${ }^{* \star} P<0.001$ versus control)

LY294002 $(50 \mu \mathrm{M})$, resulted in a $83.7 \%$ cell death $(P<0.001$ Figure $3 \mathrm{~b})$, with the cells showing cleavage of extrinsic and intrinsic caspases $8 / 9 / 3$, PARP and the associated Bid protein (Figures $4 \mathrm{a}$ and $\mathrm{b}$ ) even as early as $8 \mathrm{~h}$ of treatment. Lowering pAkt levels caused an increase in both the L\&S forms of the pro-apoptotic protein Bim, which has been important for initiating TRAIL-induced apoptosis (Figure 4b).

The completely resistant 8505 c ATC cell line can be triggered to undergo apoptosis by inhibiting two important cell survival pathways. The proliferation of the ATC cell line $8505 \mathrm{c}$ is dramatically affected by the
BRAF $^{\mathrm{V} 600 \mathrm{E}}$ inhibitor PLX4720 both in vitro and in vivo, ${ }^{12,35}$ yet ultimately PLX4720 treatment does not cause apoptosis. This cell line is also completely resistant to direct induction of apoptosis with lexatumumab (Figure 3a). As the baseline pAkt level is already very high and further increases with either lexatumumab or PLX4720 $(10 \mu \mathrm{M})$ treatment, similar to what we saw in the SW1736 cell line, we wanted to test whether the suppression of pAkt alone would trigger apoptosis. Furthermore, given previous studies emphasizing the crosstalk between the MAPK and PI3K cell survival pathways in promoting resistance to apoptosis, ${ }^{31,36,37}$ we chose to study whether dual targeting 


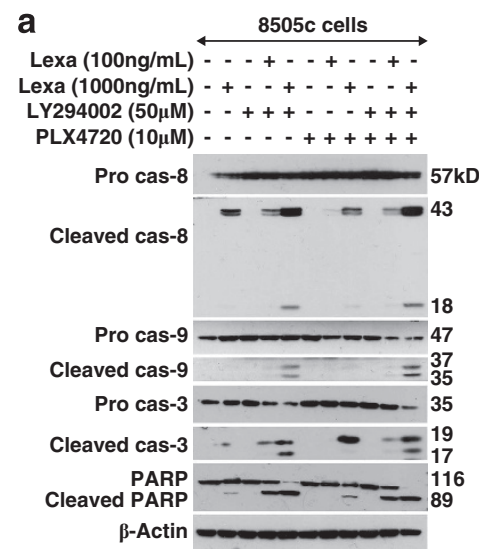

C

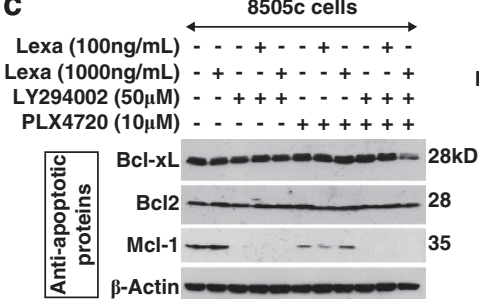

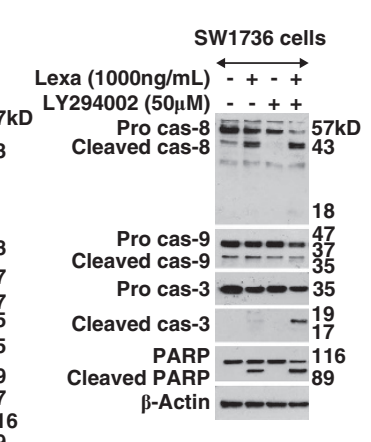

b

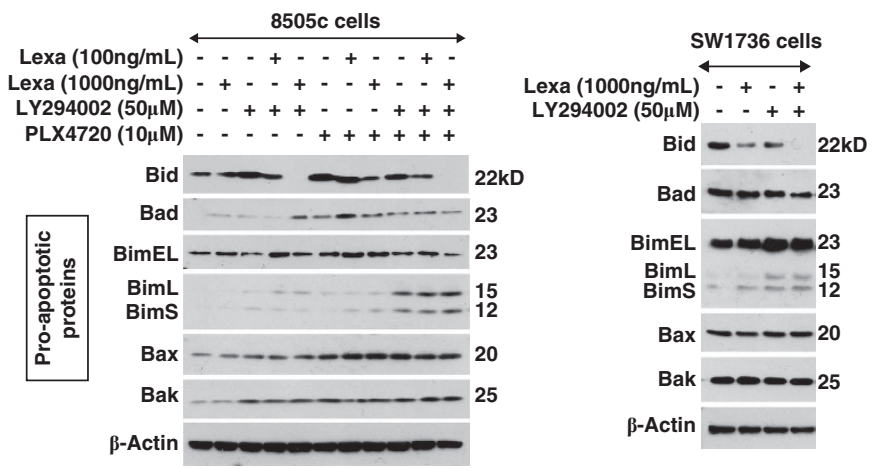

d

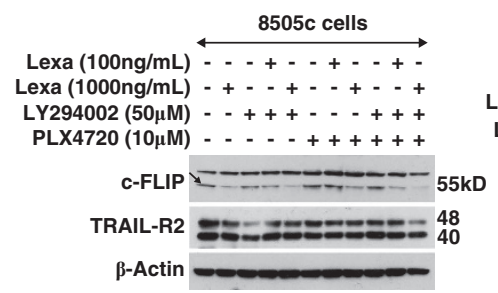

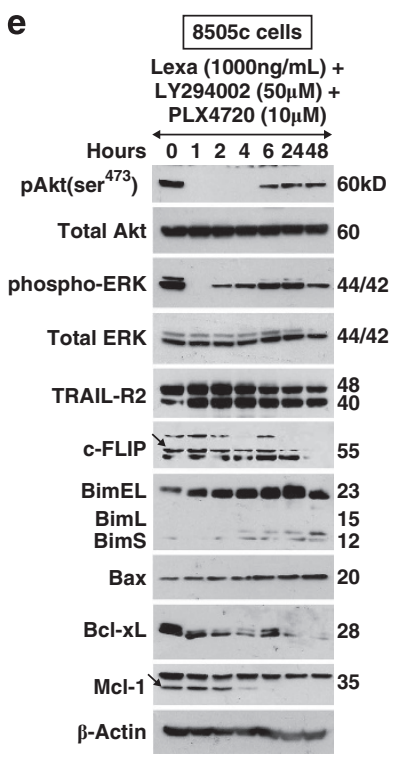

( $)$ Informative band

Figure 4 Triple-drug (LY294002, PLX4720 and lexatumumab) and dual-drug combinations (LY294002 and lexatumumab) triggered the intrinsic and extrinsic apoptotic pathways in $8505 \mathrm{c}$ and SW1736 cells. 8505c and SW1736 cells were treated for $8 \mathrm{~h}$ with drug combinations as indicated in the figure and analyzed for pro- and anti-apoptotic proteins by western blot. (a) Treatment with triple-drug combination in 8505c and the dual combination in SW1736 resulted in cleavage of caspase 8/9/3 and PARP. (b) Tripledrug combination resulted in the increase in pro-apoptotic proteins Bad, Bim, Bax and Bak in $8505 \mathrm{c}$ cells. Dual inhibitor combination, on the other hand, resulted in an increase in BimL\&S forms in SW1736 cells. (c) Triple-drug combination significantly decreased the anti-apoptotic proteins Bcl-xL and Mcl-1 in 8505c cells at $8 \mathrm{~h}$ of treatment. (d) cFLIP decreased in both the dual and triple-drug combinational treatments of $8505 \mathrm{c}$ cells. (e) Treatment of $8505 \mathrm{c}$ cells at different time points up to $48 \mathrm{~h}$ with the triple-drug combination also showed a significant decrease in anti- apoptotic proteins, Bcl-xL, Mcl-1, cFlip and an increase in pro-apoptotic proteins, Bax and Bim isoforms. $\beta$-Actin was used as loading control

of these pathways could overcome the severe resistance that $8505 \mathrm{c}$ cells have to lexatumumab-induced apoptosis. Therefore, three drugs were used singly or in combination to test our hypothesis: the MAPK/BRAF ${ }^{\mathrm{V} 600 \mathrm{E}}$ inhibitor, PLX4720 $(10 \mu \mathrm{M})$, PI3K/pAkt inhibitor, LY294002 $(50 \mu \mathrm{M})$, and lexatumumab.
No drug alone induced apoptosis in $8505 \mathrm{c}$ cells with the percentage of apoptotic cells ranging from $4.9 \pm 0.9 \%$ (lexatumumab) to $5.5 \pm 1.5 \%$ (PLX4720 $(10 \mu \mathrm{M}))$. Dual inhibition with the MAPK and PI3K inhibitors (PLX4720 and LY294002) without the apoptotic agent also did not boost apoptosis $(5.9 \pm 4.2 \%$; Figure $3 a)$. 
However, combining lexatumumab with the inhibitors of either of the two pathways did result in increased apoptosis. Dual combination of lexatumumab and LY294002 increased apoptosis to $33.1 \pm 13.2 \%, P<0.01$ (Figure $3 a$ ), whereas the dual combination with PLX4720 caused a moderate increase in apoptosis to $20.9 \pm 3.6 \%, P<0.01$. Combining all three drugs together, however, resulted in dramatic apoptosis (72.1 $\pm 3.2 \%, \quad P<0.001 ;$ Figure $3 a)$ and strong TUNEL staining (Supplementary Figure S1). Dosing curves were used to calculate optimal dosage and showed that combining these three drugs together allowed a much lower dose of lexatumumab (IC50 of $200 \mathrm{ng} / \mathrm{ml}$, data not shown) to be effective at inducing apoptosis with maximal apoptosis at $500 \mathrm{ng} / \mathrm{ml}$ (Supplementary Figure S2).

Analysis of the pro- and anti-apoptotic pathway proteins in $8505 \mathrm{c}$ cells treated with the combination of all three drugs: PLX4720 $(10 \mu \mathrm{M})$, LY294002 $(50 \mu \mathrm{M})$ and lexatumumab (1000 ng/ml) in 8505 c cells showed (Figure 4):

(a) Activation of all extrinsic and intrinsic pathways with significant cleavage of caspase-8/-9/-3 and PARP (Figure 4a).

(b) Activation of the pro-apoptotic proteins: cleavage of Bid (indicated by the decrease of pro-Bid protein; Figure $4 \mathrm{~b}$ ) and increased expression of Bad, Bak, Bim (BimL and BimS) and Bax (Figure 4b). The Bim expression was highest after $24 \mathrm{~h}$ of treatment, whereas Bax increased in expression after $1 \mathrm{~h}$ and then remained stably elevated till $24 \mathrm{~h}$ (Figure $4 \mathrm{e}$ ).

(c) Dramatic decrease in anti-apoptotic proteins - Bcl- $x \mathrm{~L}$, Mcl-1and c-FLIP - (Figures 4c and d) were reduced with treatment, even as early as after $2 \mathrm{~h}$ of treatment and remained so up to $48 \mathrm{~h}$ (Figure $4 \mathrm{e}$ ).

(d) TRAIL-R2 expression, on the other hand, increased immediately after the treatment for a short time and then progressively decreased by $48 \mathrm{~h}$ (Figure $4 \mathrm{e}$ ).

$\mathrm{Bcl}-\mathrm{xL}$ has a significant role in the resistance of $8505 \mathrm{c}$ cells to induction of apoptosis. Our results with the three drug combination confirms the work of other authors in various other malignant lines, indicating that decreased expression of anti-apoptotic protein $\mathrm{Bcl}-\mathrm{xL}$ is critical in initiation and maintenance of a robust apoptotic response to TRAIL. $22,38-41$ The $8505 \mathrm{c}$ cells started with a very high baseline $\mathrm{Bcl}-\mathrm{xL}$ protein level, which was reduced significantly after transfection with $\mathrm{Bcl}-\mathrm{xL}$ siRNA for $48 \mathrm{~h}$ (Figure $5 \mathrm{a}$ ). Subsequent treatment of these cells with lexatumumab $(1000 \mathrm{ng} / \mathrm{ml})$ resulted in $52.3 \%$ apoptosis as measured by annexinV-PE staining as well as caspase 3 and PARP cleavages compared with lexatumumab controls $(3.4 \%$ apoptosis) or scrambled siRNA (8.4\%; Figures 5b and c).

\footnotetext{
Dual inhibition of pAkt and MAPK pathways increases the lexatumumab-induced apoptosis in 8505 c orthotopic thyroid model. On the basis of our in vitro results, we predicted that the three drug combination would result in tumor apoptosis in an 8505c thyroid orthotopic model of aggressive thyroid cancer with wide spread lung metastases. Treatment was initiated 2 weeks post-orthotopic implantation of $8505 c-$ GFP cells and continued for 2 weeks with either lexatumumab (5 mg/kg body weight, IV twice a week), PLX4720 (417 mg/kg chow diet), LY294002 (50 mg/kg body
}

weight, IP twice a week) or a combination of all three drugs (Figure 6a). Controls received normal chow and saline.

Results showed that 4 weeks post-tumor implantation, treatment with lexatumumab alone $\left(76.8 \pm 15.2 \mathrm{~mm}^{3}\right)$ and LY294002 alone $\left(72.5 \pm 12.0 \mathrm{~mm}^{3}\right)$ did not result in a statistically significant decrease in tumor volume or metastasis as compared with control $\left(91.2 \pm 20.6 \mathrm{~mm}^{3}\right.$; Figures $\left.6 \mathrm{a}-\mathrm{c}\right)$. We confirmed that PLX4720 alone reduced primary tumor volume by $95 \%$ and completely treated the lung metastases compared with controls. PLX4720 treatment in vivo only resulted in $<4 \%$ of cells showing cleaved caspase- 3 by $\mathrm{IHC}$, which was not significantly increased compared with controls. The three drug combination resulted in $99 \%$ reduction in primary tumor volume, complete disappearance of lung metastases and elevated cleaved caspase 3 levels to $14 \pm 2 \%$. All the tumors in the control group and the treated groups stained positive for TTF-1 (Figure 6c). It seemed that, while the reduction in the primary tumor volume was statistically no different between PLX4720 alone and the three drug combination, given the dramatic tumor reductions in both scenarios, apoptosis was clearly only triggered with the three drug combination.

Human PTC expression profiling of apoptotic genes show a pattern of potential sensitivity to lexatumumab. If TRAIL-based therapies are to be attempted in patients with thyroid cancer, it is important to understand the basal expression of various apoptotic and death receptor gene expression profiles in thyroid cancer patient samples, compared with normal thyroid samples. Using microarray genomic data from PTC and normal thyroid samples by Giordano et al., ${ }^{42}$ we analyzed 75 genes related to apoptosis: two of these decreased, whereas seven increased in expression by at least twofold $(P<0.001)$. Expression profiles for five of these genes were then confirmed by RTPCR in a cohort of 10 human PTCs and four matched normal thyroid tissues. Those that showed more than a twofold difference in relative values of comparisons $(P<0.05)$ were considered differentially expressed. Four of the five genes had higher relative mRNA expressions in PTC samples compared with the matched normal thyroids TRAIL-R2 ( $\sim 3.2 \pm 1.4$-fold change, $P<0.05$; Figure 7a), Bax ( 3.0 \pm 2.5 -fold change, $P \leq 0.05$; Figure $7 \mathrm{~b})$, Bcl-xL ( 2.7 \pm 0.5 -fold change, $P<0.01$; Figure 7c) and Bid ( 8.2 \pm 2.5 -fold change, $P<0.001$; Figure $7 \mathrm{e}$ ). In contrast, $\operatorname{Bim}(2.9 \pm 0.92$-fold change, $P<0.01$; Figure $7 d$ ) showed a significant decrease in levels between the PTC patient tumors and normal thyroids. This pattern is similar to that seen in the sensitive BCPAP cell line.

\section{Discussion}

Aggressive thyroid cancers remain resistant to traditional chemotherapeutic agents. Novel targeted therapies are being tested in the preclinical and clinical setting for the last 5 years. Effort has been mostly focused on multikinase inhibitors such as sorafenib or targeting the BRAF or MEK pathways. Agents triggering apoptosis have not been well studied in thyroid cancer. 
a

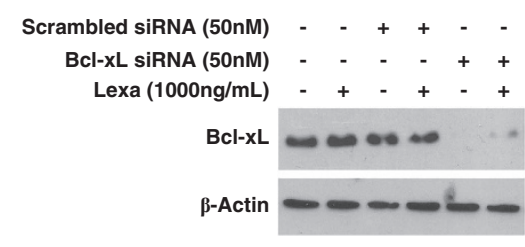

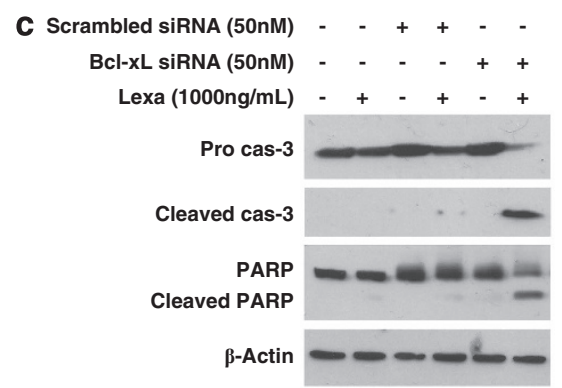

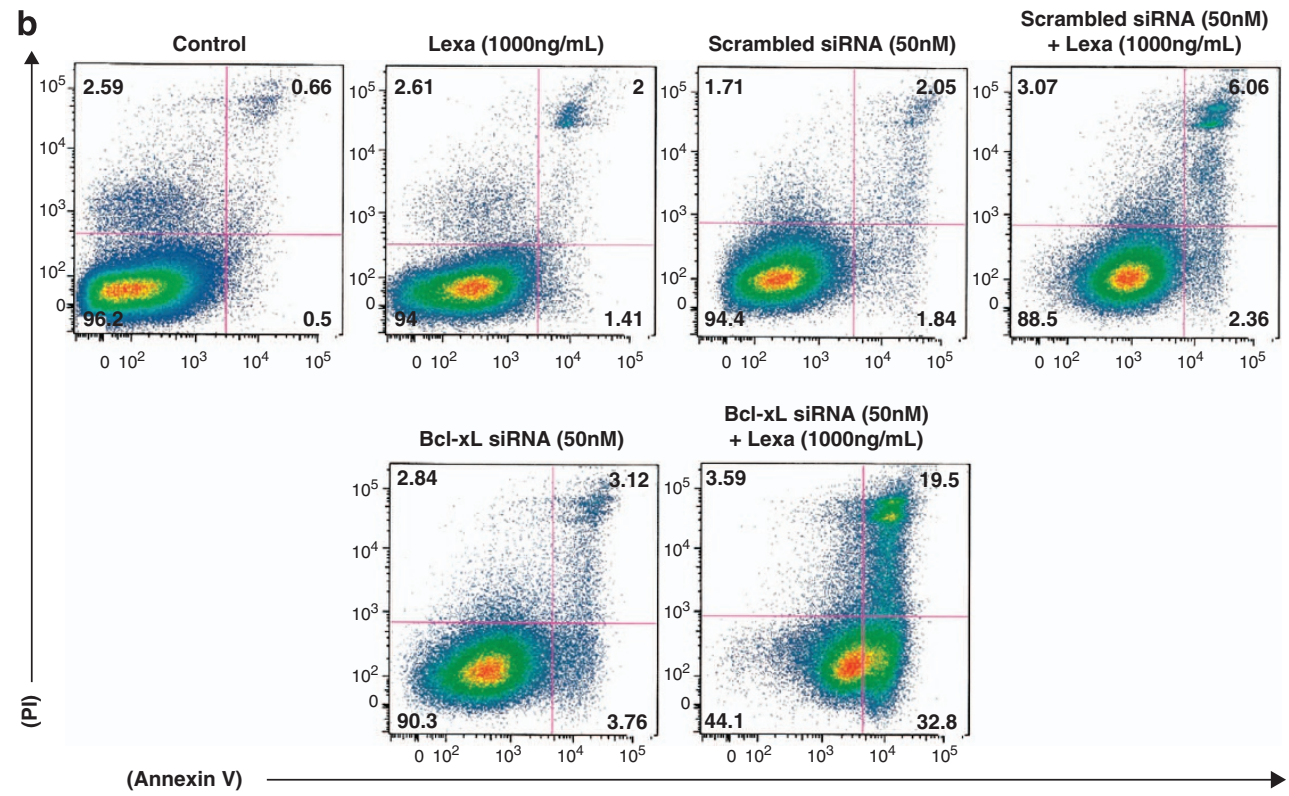

Figure 5 Knockdown of Bcl-xL sensitized $8505 \mathrm{c}$ cells to lexatumumab-induced apoptosis. Cells were transfected with $50-\mathrm{nM} \mathrm{Bcl}-\mathrm{xL}$ or control siRNA for $48 \mathrm{~h}$ and then treated with $1000 \mathrm{ng} / \mathrm{ml}$ of lexatumumab for another $24 \mathrm{~h}$. (a) Bcl-xL protein level significantly decreased after $48 \mathrm{~h}$ of transfection with Bcl-xL siRNA. $\beta$-Actin served as a loading control. (b) Treatment of Bcl-xL knockdown cells with lexatumumab showed a significant increase in cell death $(52.3 \%, P<0.01$ versus control) as measured by annexinV-PE staining; the treated cells showed the cleavage of caspase-3 and PARP (c)

We report here for the first time the efficacy of the pro-apoptotic TRAIL-receptor 2 agonist, lexatumumab, in inducing apoptosis in a variety of representative thyroid cancer cells with well-defined mutations that include BRAF ${ }^{\mathrm{V} 600 \mathrm{E}}$ (BCPAP, 8505c, SW1736), NRAS ${ }^{\mathrm{Q} 1 \mathrm{R}}$ (HTh-7) and RET/ PTC (TPC-1). We observed a range of apoptotic responses to lexatumumab, with some being exquisitely sensitive (TPC-1, HTh-7 and BCPAP), whereas others were moderately or completely resistant (SW1736 and 8505c). Interestingly, the mutational status alone did not show a direct correlation to lexatumumab sensitivity. When exposed to lexatumumab, the sensitive cell lines were able to efficiently and rapidly activate both extrinsic and intrinsic apoptotic pathways. As there was a strong apoptotic response ranging from 83 to $99 \%$ in the three sensitive cell lines, we tested the in vivo efficacy of this novel antibody in an orthotopic animal model of thyroid cancer using one of the sensitive cell lines, BCPAP. Our results showed that lexatumumab treatment alone induced apoptosis in vivo, which resulted in effective tumor shrinkage of $67 \%$, indicating the potential utility of this agent in some patients with papillary or ATCs. Furthermore, expression profiling of five genes known to be important in regulating the apoptotic response to lexatumumab showed that all 10 PTC samples directly from patients had profiles that were similar to the BCPAP PTC cell line, which we have shown here to be exquisitely sensitive to TRAIL-induced apoptosis.

Not surprisingly, the most aggressive ATC cell line we studied, $8505 \mathrm{c}$, showed remarkable resistance to apoptosis with $<5 \%$ of cells undergoing apoptosis even when exposed to high doses of lexatumumab. These data are consistent with our previous studies showing that this cell line is generally resistant to apoptosis when treated with other agents. ${ }^{22,23,40}$ We were able to induce apoptosis in this resistant cell line by combining lexatumumab with a PI3K/Akt inhibitor LY294002 and a BRAF ${ }^{\mathrm{V} 600 \mathrm{E}}$ inhibitor PLX4720. Our combinatorial strategy that was guided by known signaling pathway and genomic data led to rapid and sustained apoptosis in vitro and in vivo. Although PLX4720 alone effectively reduced the tumor volume and the lung metastasis, it failed to induce apoptosis in the tumor cells in vivo. Development of resistance to PLX4720 is a major limitation when it comes to efficacy in treating patients as recurrent tumor growth occurs from the few remaining cells that have not undergone apoptosis. This study points to the utility of the three-drug combination in inducing apoptosis in the $8505 \mathrm{c}$ orthotopic tumors along with the rapid tumor shrinkage and 
a
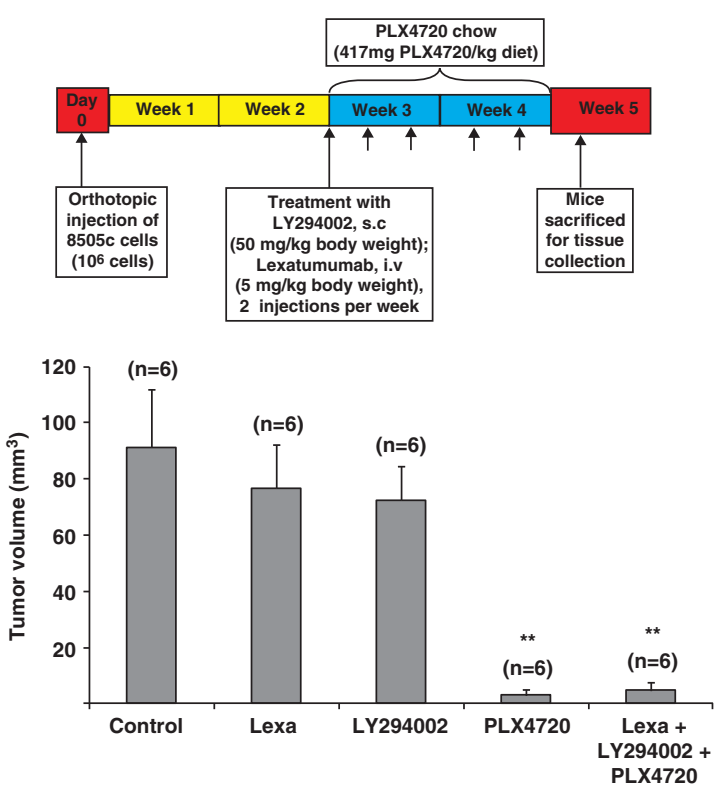

b

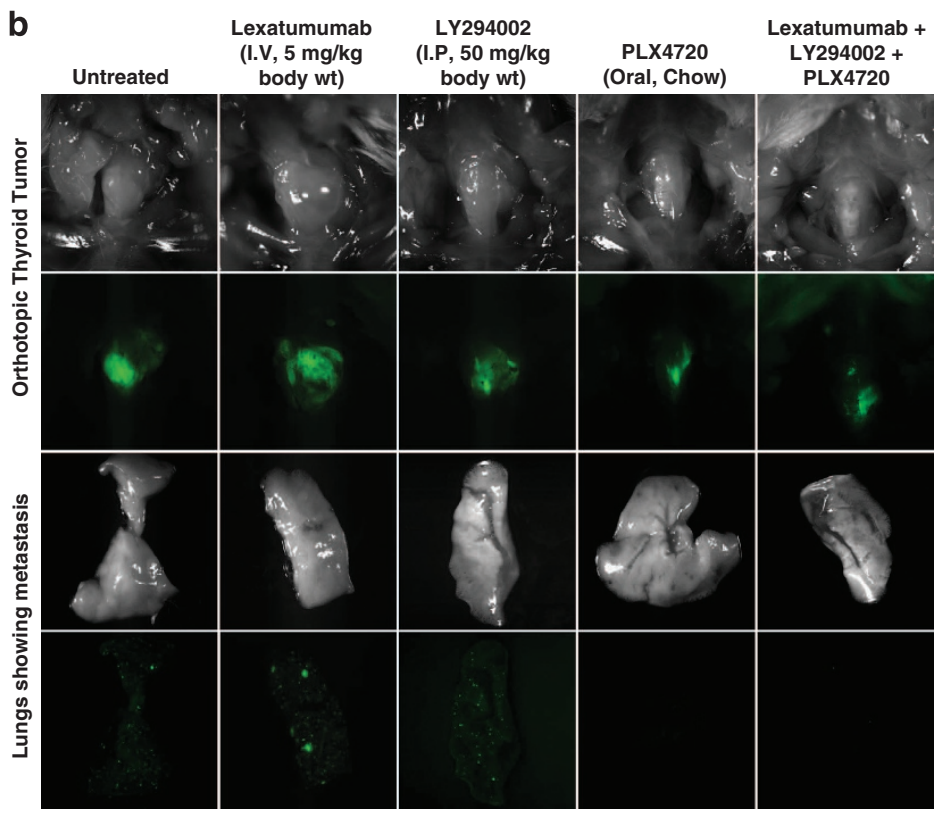

c

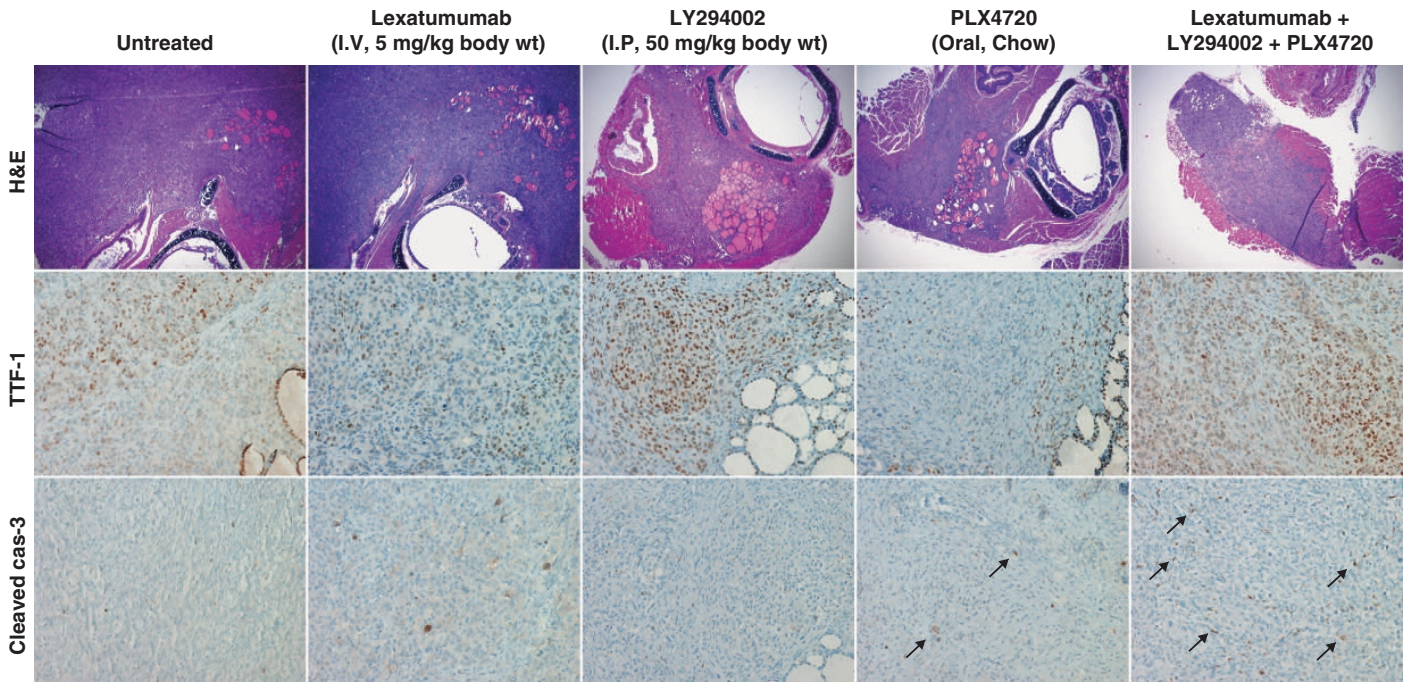

Figure 6 Treatment with the triple-drug combination (LY294002, PLX4720 and lexatumumab) increased apoptosis in 8505c-originated orthotopic thyroid tumors. One million $8505 \mathrm{c}$ cells were implanted into the left thyroid of the SCID mouse. (a) Two weeks post implantation, the mice (six mice/group) were treated for another 2 weeks with lexatumumab (5 mg/kg body weight, I.V twice every week), PLX4720 (417 mg/kg chow diet), LY294002 (50 mg/kg body weight, I.P twice every week) separately as single agents, whereas one group received the triple combination drugs. Control group of mice received saline and fed on the normal chow. Treatment with single drug agents did not significantly decrease tumor volume compared with control $\left(91.2 \pm 20.6 \mathrm{~mm}^{3}\right)$ : lexatumumab $\left(76.8 \pm 15.2 \mathrm{~mm}^{3}\right)$ and LY294002 $\left(72.5 \pm 12.0 \mathrm{~mm}^{3}\right)$. Mice receiving either PLX4720 alone or the triple-drug combination showed dramatic decreases in tumor volume $\left(4.6 \pm 3.1 \mathrm{~mm}^{3}\right)$. $\left({ }^{* \star} P<0.001\right.$ versus control). (b) GFP imaging of the thyroid orthotopic tumors and lung confirmed reductions in the primary tumor and metastasis. (c) All tumors showed aggressive histology and expressed TTF-1. Triple-drug therapy significantly increased the levels of apoptotic cells in the tumor, as measured by cleaved caspase-3 IHC staining compared with single agent therapy with PLX4720 (14 $\pm 2 \%$ versus $<4 \%$ )

reduction of lung metastasis. This study among others can lead to better long-term outcomes. Our data showed that two critical elements had a role in the marked resistance to apoptosis in this cell line (Figure 8b). The 8505 c cells had both a very high baseline expression of $\mathrm{Bcl}-\mathrm{xL}$ and a low expression of Bax (low Bax/Bcl-xL ratio) and when exposed to lexatumumab treatment mounted a remarkable increase in pAkt levels. As pAkt is a well-known anti-apoptotic protein, a sudden increase in pAkt when exposed to the apoptotic agent is in sharp contrast to the sensitive cell lines, which show suppression of pAkt levels. Inhibition of pAkt by LY294002 or knockdown of $\mathrm{Bax} / \mathrm{Bcl}-\mathrm{xL}$ protein ratio alone did somewhat increase the apoptotic response to $30 \%$; however, only when the three-drug combination was used were these cells able to mount an apoptotic response up to $68 \%$.

The 'crosstalk' between apoptotic and various kinase pathways is just starting to be studied in other malignancies. In colorectal cancer, resistance to apoptosis is thought to be due to dual mutations in the PI3 and MAP Kinase pathways 


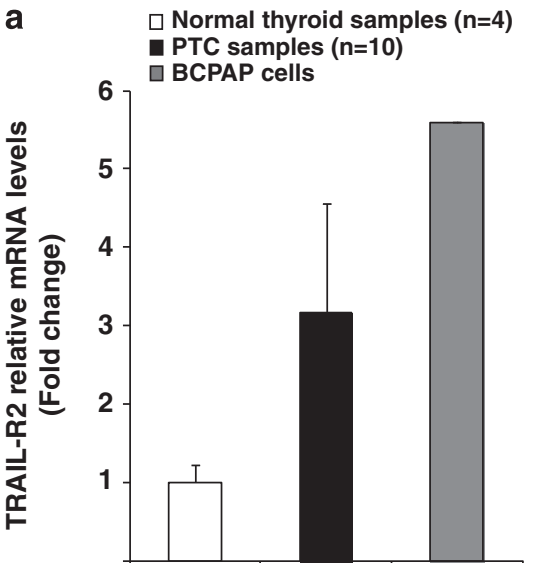

TRAIL-R2

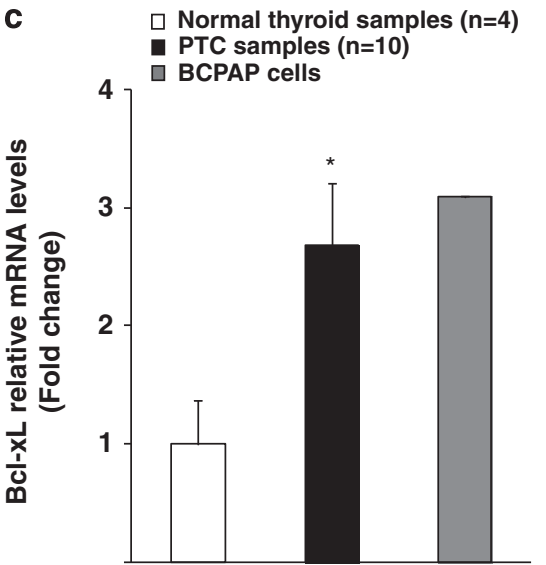

Bcl-xL

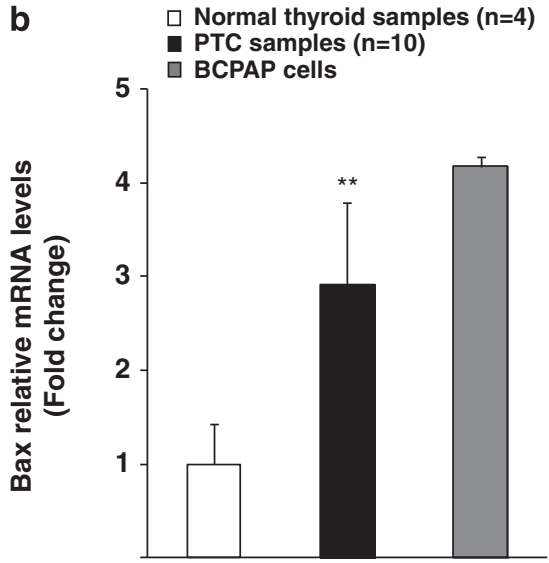

Bax

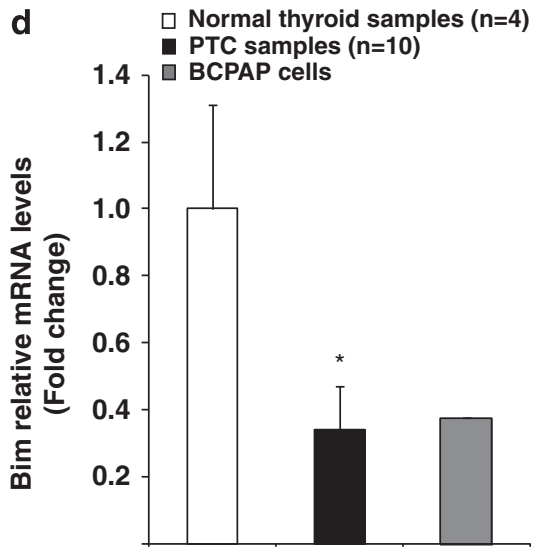

Bim

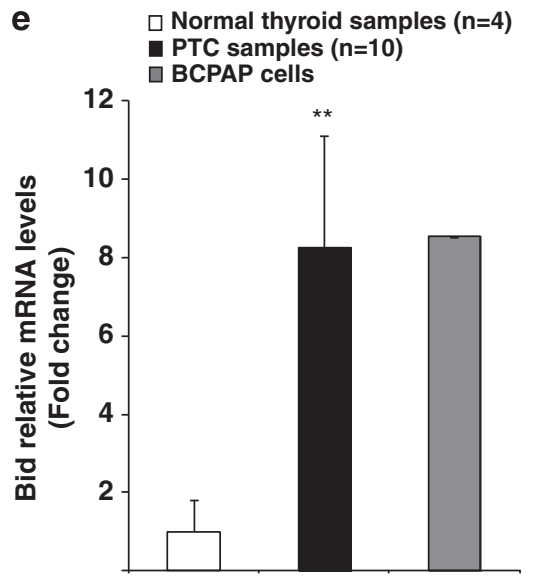

Bid

Figure 7 Relative real-time RT-PCR of Bax, Bcl-xL, Bim, Bid and TRAIL-R2 in patient PTC samples $(n=10)$ compared with matched normal thyroid tissue (NT; $n=4)$. (a) TRAIL-R2 was upregulated $\sim 3.2 \pm 1.4$-fold $(P<0.05)$ in PTCs versus normal thyroid. (b) Bax was upregulated $\sim 3.0 \pm 2.5$-fold $(P \leq 0.05)$ in PTCs versus normal thyroid. (c) Bcl-xL was upregulated $\sim 2.7 \pm 0.5$-fold $(P<0.01)$ in PTCs versus normal thyroid. (d) Bim was downregulated $\sim 2.9 \pm 0.92$-fold $(P<0.01)$ in PTCs versus normal thyroid. (e) Bid was upregulated $\sim 8.2 \pm 2.5$-fold $(P<0.01)$ in PTCs versus normal thyroid. $\left({ }^{*} P<0.01\right.$ and $\left.{ }^{* *} P<0.001\right)$

(PIK3CA $^{\mathrm{H} 1047}$ and BRAF $\left.{ }^{\mathrm{V} 600 \mathrm{E}}\right)$, which cause high levels of pAkt, thus blocking TRAIL-induced apoptosis. In melanoma and non-small cell lung carcinoma, high basal or induced pAkt protein levels conferred resistance to apoptosis by MEK inhibitors. ${ }^{31,43,44}$ Here we have shown that in thyroid cancer, resistance to apoptosis follows a similar pattern. The ATC cell line $8505 \mathrm{c}$ demonstrates a remarkable decrease in proliferation when exposed to BRAF ${ }^{\mathrm{V} 600 \mathrm{E}}$ inhibitor PLX4720; however, unfortunately there is a simultaneous detrimental further increase in pAkt levels that essentially prevents the initiation 


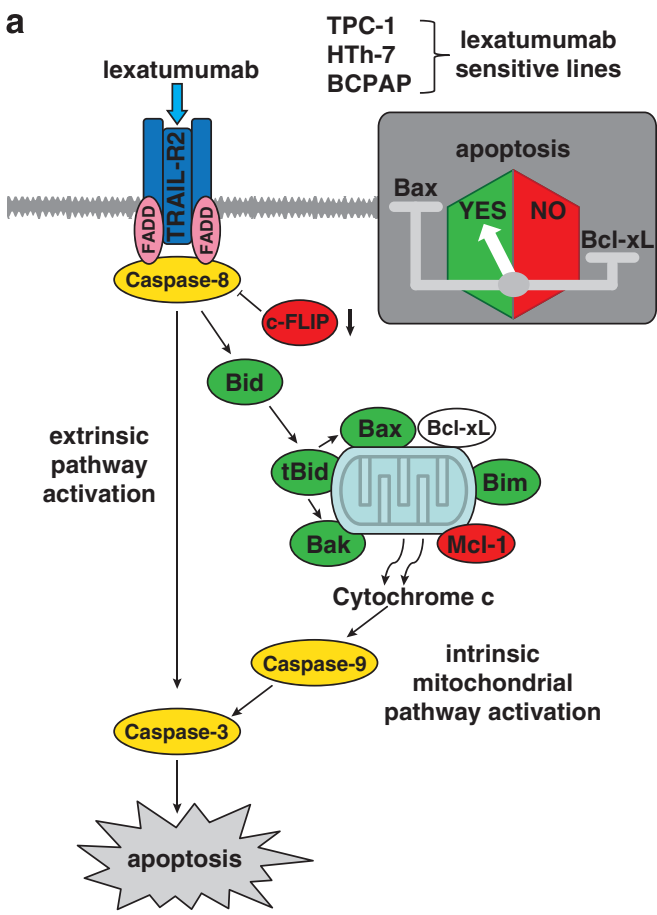

b

Figure 8 Schematic diagram showing differences in the thyroid cancer cell lines sensitive or resistant to apoptosis. (a) Lexatumumab induced dramatic apoptosis results in sensitive cell lines (TPC-1, HTh-7 and BCPAP) through activation of both intrinsic and extrinsic pathways. (b) 8505c cells show complete resistance to lexatumumab-induced apoptosis, but effective apoptosis can be triggered by removing the 'block' to apoptosis by using addition of PLX4720 and LY294002, through re-activation of the intrinsic mitochondrial pathway

of apoptosis. Our three-drug combination is likely effective due to effects on multiple fronts. Most importantly, the inhibition of both pAkt and the MAPK pathway controls the regulatory increase in alternative pathways caused by the other's negated pathway. In addition, beneficial alterations in the ratios of pro-apoptotic proteins, Bax and Bak, protein expressions and the anti-apoptotic proteins, $\mathrm{Bcl}-\mathrm{xL}, \mathrm{Mcl}-1$ and cFLIP, favors overcoming the resistance to TRAIL. ${ }^{45,46}$ 
Finally, elevations in all three isoforms of Bim contribute to a higher apoptotic response. ${ }^{47,48}$

Interestingly, we also found that one ATC cell line had an intermediate sensitivity to lexatumumab - SW1736, showing a $24 \%$ cell death response. This cell line already has a high $\mathrm{Bax} / \mathrm{Bcl}-\mathrm{xL}$ ratio similar to all the sensitive cell lines; therefore, we hypothesized that the resistance to apoptosis was likely due to an increase in pAkt when exposed to lexatumumab. Dual-drug combination of a pAkt inhibitor along with lexatumumab triggered increased cell death up to $84 \%$, indicating the importance of inhibition of the pAkt pathway alone in this intermediately sensitive cell line.

We have shown here that some thyroid cancer cell lines are sensitive to apoptotic agents and these agents should be tried clinically in appropriate patients. Appropriate patients may include those with no known mutations, high levels of TRAIL$\mathrm{R} 2$ receptor and a high $\mathrm{Bax}$ to $\mathrm{Bcl}-\mathrm{xL}$ ratio, as these patients have elements to suggest that their tumors will be sensitive to apoptotic agents alone. Patients with either activating mutations in the PI3K or MAPK pathways and/or a low baseline Bax to $\mathrm{Bcl}-\mathrm{XL}$ ratio may need a combination of pro-apoptotic agents such as lexatumumab with kinase inhibitors to show efficacy. Further studies in genetically engineered models of aggressive thyroid cancer in mice, which harbor additional mutations such as p53 and BRAF, ${ }^{49,50}$ will undoubtedly shed light on the true efficacy of a combinatorial strategy.

\section{Materials and methods}

Cell culture, antibodies and reagents. Reagents included the following: lexatumumab (Human Genome Sciences, GlaxoSmithKline, Philadelphia, PA, USA), LY294002 (Cell Signaling Technology, Danvers, MA, USA) and PLX4720 (Plexxikon, Berkeley, CA, USA). Antibodies - $\beta$-actin, phospho-p44/42 MAPK (ERK1/2) (Thr202/Tyr204) (phospho-ERK), p44/42 MAPK (ERK1/2) (Total ERK), total Akt, phospho-Akt $\left(\mathrm{Ser}^{473}\right)$, caspases 3,8,9, cleaved caspase-3, PARP, c-FLIP, TRAIL-R2, Bcl2, Bcl-xL, Mcl-1, Bim, Bid, Bax, Bad, Bak were purchased from Cell Signaling Technology.

ATC cell lines - 8505 $\left(\mathrm{BRAF}^{\mathrm{V} 600 \mathrm{E} /-}\right)$, SW1736 $\left(\mathrm{BRAF}^{\mathrm{V} 600 \mathrm{E} / \mathrm{wt}}\right)$, HTh-7 $\left(\right.$ NRAS $\left.^{\text {Q61R }}\right)$; PTC cell lines - BCPAP (BRAF $\left.{ }^{\mathrm{V} 600 \mathrm{E} / \mathrm{wt}}\right)$, TPC-1 (RET/PTC-1); and normal thyroid cell line - HTori were grown in RPMl1640 medium with 10\% FBS and Penicillin (100 units/ml)/streptomycin (100 $\mu \mathrm{g} / \mathrm{ml})$ (Gibco, Grand Island, NY, USA).

Apoptosis assays and western blots. Treatment was carried out at 60 $70 \%$ confluency. BCPAP, HTh-7 and TPC-1 cells were treated with lexatumumab $(1000 \mathrm{ng} / \mathrm{ml})$ for $24 \mathrm{~h}$, whereas $8505 \mathrm{c}$ and SW1736 cells received treatment with lexatumumab alone or in combination with LY294002 $(50 \mu \mathrm{M})$ and PLX4720 $(10 \mu \mathrm{M})$ for $48 \mathrm{~h}$. The percent of apoptotic cells was assayed by flow cytometry (BD Sorp 8 Laser LSR II (BD Biosciences, San Jose, CA, USA) using annexinV-PE Apoptosis Detection Kit (BD Biosciences). Flow cytometry data were analyzed using FlowJo (Tree Star Inc., Ashland, OR, USA).

For determining the IC50 and response curves of lexatumumab, 10000 cells were treated with a wide range of lexatumumab concentrations for $72 \mathrm{~h}$ and cell viability was tested using CellTiter96 Aqueous One Solution Reagent for the MTS assay (Promega, Madison, WI, USA).

For terminal deoxynucleotidyl transferase-mediated dUTP nick end labeling (TUNEL) assay, cells were fixed with $1 \%$ paraformaldehyde in cold PBS and processed using the APO-BrdU TUNEL kit (Invitrogen, Grand Island, NY, USA), and apoptotic cells were counted using fluorescence.

For western blot analysis, all the drug treatments were carried out for $8 \mathrm{~h}$ at 60 $70 \%$ cell confluency. At the end of the treatment, the cells were lysed on ice in RIPA buffer containing protease and phosphatase inhibitor cocktail (Thermo Scientific, Rockford, IL, USA). Western blot assay was performed using standard procedure. ${ }^{10}$

SiRNA knockdown. A total of $1 \times 10^{5} 8505 \mathrm{c}$ cells were transfected with either $50 \mathrm{nM}$ of $\mathrm{Bcl}-\mathrm{xL}$ siRNA (siGENOME SMARTpool) or scrambled siRNA
(Dharmacon/Thermo Fisher Scientific Inc.), using Dharmafect2 and incubated for $48 \mathrm{~h}$ to achieve $\mathrm{Bcl}-\mathrm{xL}$ protein knockdown. Cells were then treated with lexatumumab $(1000 \mathrm{ng} / \mathrm{ml})$ for $24 \mathrm{~h}$ and assayed for apoptosis.

Real-time PCR. Real-time PCR was performed and analyzed using Lightcycler 96 (Roche) qPCR machine and its software, normalized to GAPDH expression as described previously. ${ }^{10}$ Primer sequences include: TRAIL-R2 (forward): $5^{\prime}$-ACCACGACCAGAACACAG- $3^{\prime}$ and (reverse): $5^{\prime}$-CATTCGATGTCA CTCCAGGG-3'; BCl-xL (forward): $5^{\prime}$-GTGGAAAGCGTAGACAAGGAG-3' and (reverse): 5'-CTGCATTGTTCCCATAGAGTTC-3'; Bax (forward): 5'-AGTAACATG GAGCTGCAGAG- $3^{\prime}$ and (reverse): $5^{\prime}$-AGTAGAAAAGGGCGACAACC-3'; Bid (forward): $5^{\prime}$-ATTAACCAGAACCTACGCACC-3' and (reverse): $5^{\prime}$-TGACCACATC GAGCTTTAGC-3'; Bim (forward): $5^{\prime}$-TCGGACTGAGAAACGCAAG-3' and (reverse): 5'-CTCGGTCACACTCAGAACTTAC-3'.

Orthotopic thyroid cancer model and pathologic analysis. All animal work was conducted at the Massachusetts General Hospital in accordance with the federal, local and institutional guidelines. For orthotopic tumor implantations, 10-week-old female SCID mice were injected with $10^{6}$ tumor cells as previously described: ${ }^{32} 12$ animals had BCPAP cells implanted (6/group), and 40 animals had $8505 \mathrm{c}$-GFP cells injected (8/group) ${ }^{32}$ At the end of treatment, the mice were killed and the tumor volume was calculated as $(\pi / 6) \times$ length $\times$ width $\times$ height. Tumor growth inhibition (TGI) was determined using: $\mathrm{TGI}=(1-$ treatment/control) $\times 100$. GFP imaging was performed using multispectral fluorescence scanner (CRi Maestro 500, CRi Inc.). Tumors were collected in $10 \%$ formalin for H\&E, TUNEL, TTF-1 and cleaved caspase-3. In case of mice injected with $8505 \mathrm{c}-$ GFP cells, the tumors were collected at the end of 1-week treatment for the $\mathrm{IHC}$ analysis.

Statistical analysis. Statistical analysis was carried out using Microsoft Excel (Microsoft, Redmond, VA, USA) and GraphPad Prism (GraphPad, La Jolla, CA, USA). All experiments were performed at least three times, and the results were expressed as mean \pm S.D. of the individual experiments. Results were compared using the unpaired, two-tailed Student's $t$-test; $P$-values of $<0.05$ were considered significant $\left({ }^{\star} P<0.01,{ }^{* *} P<0.001\right)$.

\section{Conflict of Interest}

The authors declare no conflict of interest.

Acknowledgements. We thank Gideon Bollag, Paul Lin at Plexxikon/Roche for providing us with PLX4720; and Matthew Nehs and Andrew Scott Liss for technical assistance. This work was supported by The National Institutes of Health grant to Dr. Sareh Parangi (NIH-NCI R01 1R01CA149738-01A1).

1. Simard EP, Ward EM, Siegel R, Jemal A. Cancers with increasing incidence trends in the United States: 1999 through 2008. CA Cancer J Clin 2012; 62: 118-128.

2. Baudin $E$, Schlumberger $M$. New therapeutic approaches for metastatic thyroid carcinoma. Lancet Oncol 2007; 8: 148-156.

3. Smallridge RC, Marlow LA, Copland JA. Anaplastic thyroid cancer: molecular pathogenesis and emerging therapies. Endocr Relat Cancer 2009; 16: 17-44.

4. Xing M. BRAF mutation in papillary thyroid cancer: pathogenic role, molecular bases, and clinical implications. Endocr Rev 2007; 28: 742-762.

5. Elisei R, Ugolini C, Viola D, Lupi C, Biagini A, Giannini R et al. BRAF(V600E) mutation and outcome of patients with papillary thyroid carcinoma: a 15-year median follow-up study. J Clin Endocrinol Metab 2008; 93: 3943-3949.

6. Frasca F, Nucera C, Pellegriti G, Gangemi P, Attard M, Stella M et al. BRAF(V600E) mutation and the biology of papillary thyroid cancer. Endocr Relat Cancer 2008; 15: 191-205.

7. Davies H, Bignell GR, Cox C, Stephens P, Edkins S, Clegg S et al. Mutations of the BRAF gene in human cancer. Nature 2002; 417: 949-954

8. Wan PT, Garnett MJ, Roe SM, Lee S, Niculescu-Duvaz D, Good VM et al. Mechanism of activation of the RAF-ERK signaling pathway by oncogenic mutations of B-RAF. Cell 2004; 116: 855-867.

9. Mitsiades CS, Negri J, McMullan C, McMillin DW, Sozopoulos E, Fanourakis G et al. Targeting BRAFV600E in thyroid carcinoma: therapeutic implications. Mol Cancer Ther 2007; 6: 1070-1078.

10. Nucera C, Nehs MA, Nagarkatti SS, Sadow PM, Mekel M, Fischer AH et al. Targeting BRAFV600E with PLX4720 displays potent antimigratory and anti-invasive activity in preclinical models of human thyroid cancer. Oncologist 2011; 16: 296-309. 
11. Nehs MA, Nagarkatti S, Nucera C, Hodin RA, Parangi S. Thyroidectomy with neoadjuvant PLX4720 extends survival and decreases tumor burden in an orthotopic mouse model of anaplastic thyroid cancer. Surgery 2010; 148: 1154-1162.

12. Salerno P, De Falco V, Tamburrino A, Nappi TC, Vecchio G, Schweppe RE et al. Cytostatic activity of adenosine triphosphate-competitive kinase inhibitors in BRAF mutant thyroid carcinoma cells. J Clin Endocrinol Metab 2010; 95: 450-455.

13. Abdulghani J, El-Deiry WS. TRAIL receptor signaling and therapeutics. Expert Opin Ther Targets 2010; 14: 1091-1108.

14. Malin D, Chen F, Schiller C, Koblinski J, Cryns VL. Enhanced metastasis suppression by targeting TRAIL receptor 2 in a murine model of triple-negative breast cancer. Clin Cancer Res 2011; 17: 5005-5015.

15. Merchant MS, Geller JI, Baird K, Chou AJ, Galli S, Charles A et al. Phase I trial and pharmacokinetic study of lexatumumab in pediatric patients with solid tumors. $J$ Clin Oncol 2012; 30: 4141-4147.

16. Wakelee HA, Patnaik A, Sikic BI, Mita M, Fox NL, Miceli $R$ et al. Phase I and pharmacokinetic study of lexatumumab (HGS-ETR2) given every 2 weeks in patients with advanced solid tumors. Ann Oncol 2010; 21: 376-381.

17. Plummer R, Attard G, Pacey S, Li L, Razak A, Perrett R et al. Phase 1 and pharmacokinetic study of lexatumumab in patients with advanced cancers. Clin Cancer Res 2007; 13: 6187-6194.

18. Ren B, Song K, Parangi S, Jin T, Ye M, Humphreys $R$ et al. A double hit to kill tumor and endothelial cells by TRAIL and antiangiogenic 3TSR. Cancer Res 2009; 69 : 3856-3865.

19. Zhang L, Zhang X, Barrisford GW, Olumi AF. Lexatumumab (TRAlL-receptor $2 \mathrm{mAb}$ ) induces expression of DR5 and promotes apoptosis in primary and metastatic renal cell carcinoma in a mouse orthotopic model. Cancer Lett 2007; 251: 146-157.

20. Bangert A, Cristofanon S, Eckhardt I, Abhari BA, Kolodziej S, Hacker S et al. Histone deacetylase inhibitors sensitize glioblastoma cells to TRAlL-induced apoptosis by c-myc-mediated downregulation of cFLIP. Oncogene 2012; 31: 4677-4688.

21. Morissette MC, Vachon-Beaudoin G, Parent J, Chakir J, Milot J. Increased p53 level, Bax/ $\mathrm{Bcl}-\mathrm{x}(\mathrm{L})$ ratio, and TRAIL receptor expression in human emphysema. Am J Respir Crit Care Med 2008; 178: 240-247.

22. Bansal H, Seifert T, Bachier C, Rao M, Tomlinson G, lyer SP et al. The transcription factor Wilms tumor 1 confers resistance in myeloid leukemia cells against the proapoptotic therapeutic agent TRAIL (tumor necrosis factor alpha-related apoptosis-inducing ligand) by regulating the antiapoptotic protein Bcl-xL. J Biol Chem 2012; 287: 32875-32880.

23. Fulda S. Tumor resistance to apoptosis. Int J Cancer 2009; 124: 511-515.

24. Dolloff NG, Mayes PA, Hart LS, Dicker DT, Humphreys R, El-Deiry WS. Off-target lapatinib activity sensitizes colon cancer cells through TRAIL death receptor up-regulation. Sci Transl Med 2011; 3: 86ra50.

25. Zhao X, Cao M, Liu JJ, Zhu H, Nelson DR, Liu C. Reactive oxygen species is essential for cycloheximide to sensitize lexatumumab-induced apoptosis in hepatocellular carcinoma cells. PLoS One 2011; 6: e16966.

26. Wu XX, Kakehi Y. Enhancement of lexatumumab-induced apoptosis in human solid cancer cells by Cisplatin in caspase-dependent manner. Clin Cancer Res 2009; 15: 2039-2047.

27. Engesaeter B, Engebraaten O, Florenes VA, Maelandsmo GM. Dacarbazine and the agonistic TRAIL receptor-2 antibody lexatumumab induce synergistic anticancer effects in melanoma. PLOS One 2012; 7: e45492.

28. Dieterle A, Orth R, Daubrawa M, Grotemeier A, Alers S, Ullrich S et al. The Akt inhibitor triciribine sensitizes prostate carcinoma cells to TRAIL-induced apoptosis. Int $\mathrm{J}$ Cancer 2009; 125: 932-941.

29. Opel D, Naumann I, Schneider M, Bertele D, Debatin KM, Fulda S. Targeting aberrant PI3K/Akt activation by Pl103 restores sensitivity to TRAIL-induced apoptosis in neuroblastoma. Clin Cancer Res 2011; 17: 3233-3247.

30. Shao Y, Aplin AE. Akt3-mediated resistance to apoptosis in B-RAF-targeted melanoma cells. Cancer Res 2010; 70: 6670-6681.

31. Oikonomou E, Koc M, Sourkova V, Andera L, Pintzas A. Selective BRAFV600E inhibitor PLX4720, requires TRAIL assistance to overcome oncogenic PIK3CA resistance. PLoS One 2011; 6: e21632.

32. Nucera C, Nehs MA, Mekel M, Zhang X, Hodin R, Lawler J et al. A novel orthotopic mouse model of human anaplastic thyroid carcinoma. Thyroid 2009; 19: 1077-1084.
33. Chan CM, Jing X, Pike LA, Zhou Q, Lim DJ, Sams SB et al. Targeted inhibition of Src kinase with dasatinib blocks thyroid cancer growth and metastasis. Clin Cancer Res 2012; 18: 3580-3591.

34. Aplin AE, Kaplan FM, Shao Y. Mechanisms of resistance to RAF inhibitors in melanoma. $J$ Invest Dermatol 2011; 131: 1817-1820.

35. Nucera C, Lawler J, Hodin R, Parangi S. The BRAFV600E mutation: what is it really orchestrating in thyroid cancer? Oncotarget 2010; 1: 751-756.

36. Jin N, Jiang T, Rosen DM, Nelkin BD, Ball DW. Dual inhibition of mitogen-activated protein kinase kinase and mammalian target of rapamycin in differentiated and anaplastic thyroid cancer. J Clin Endocrinol Metab 2009; 94: 4107-4112.

37. Martelli AM, Tazzari PL, Tabellini G, Bortul R, Billi AM, Manzoli L et al. A new selective AKT pharmacological inhibitor reduces resistance to chemotherapeutic drugs, TRAlL, all-transretinoic acid, and ionizing radiation of human leukemia cells. Leukemia 2003; 1 : 1794-1805.

38. Martinez-Paniagua MA, Baritaki S, Huerta-Yepez S, Ortiz-Navarrete VF, Gonzalez-Bonilla $\mathrm{C}$, Bonavida $\mathrm{B}$ et al. Mcl-1 and $\mathrm{YY} 1$ inhibition and induction of DR5 by the BH3-mimetic Obatoclax (GX15-070) contribute in the sensitization of B-NHL cells to TRAIL apoptosis. Cell Cycle 2011; 10: 2792-2805.

39. Hinz S, Trauzold A, Boenicke L, Sandberg C, Beckmann S, Bayer E et al. Bcl-XL protects pancreatic adenocarcinoma cells against CD95- and TRAlL-receptor-mediated apoptosis. Oncogene 2000; 19: 5477-5486.

40. Zhu H, Guo W, Zhang L, Davis JJ, Wu S, Teraishi F et al. Enhancing TRAlL-induced apoptosis by $\mathrm{Bcl}-\mathrm{X}(\mathrm{L})$ siRNA. Cancer Biol Ther 2005; 4: 393-397.

41. Chawla-Sarkar M, Bae SI, Reu FJ, Jacobs BS, Lindner DJ, Borden EC. Downregulation of Bcl-2, FLIP or IAPs (XIAP and survivin) by siRNAs sensitizes resistant melanoma cells to Apo2L/TRAIL-induced apoptosis. Cell Death Differ 2004; 11: 915-923.

42. Giordano TJ, Kuick R, Thomas DG, Misek DE, Vinco M, Sanders D et al. Molecular classification of papillary thyroid carcinoma: distinct BRAF, RAS, and RET/PTC mutationspecific gene expression profiles discovered by DNA microarray analysis. Oncogene 2005; 24: $6646-6656$.

43. Meng J, Dai B, Fang B, Bekele BN, Bornmann WG, Sun D et al. Combination treatment with MEK and AKT inhibitors is more effective than each drug alone in human non-small cell lung cancer in vitro and in vivo. PLoS One 2010; 5: e14124.

44. Ivanov VN, Bhoumik A, Ronai Z. Death receptors and melanoma resistance to apoptosis. Oncogene 2003; 22: 3152-3161.

45. Berger A, Quast SA, Plotz M, Kuhn NF, Trefzer U, Eberle J. RAF inhibition overcomes resistance to TRAIL-induced apoptosis in melanoma cells. J Invest Dermatol 2013; 134: 430-440.

46. Leahomschi S, Molinsky J, Klanova M, Andera L, Peterka M, Gasova Z et al. Multi-level disruption of the extrinsic apoptotic pathway mediates resistance of leukemia cells to TNF-related apoptosis-inducing ligand (TRAIL). Neoplasma 2013; 60: 223-231.

47. Romano G, Acunzo M, Garofalo M, Di Leva G, Cascione L, Zanca C et al. MiR-494 is regulated by ERK1/2 and modulates TRAlL-induced apoptosis in non-small-cell lung cancer through BIM down-regulation. Proc Natl Acad Sci USA 2012; 109: 16570-16575.

48. Badmann A, Langsch S, Keogh A, Brunner T, Kaufmann T, Corazza N. TRAIL enhances paracetamol-induced liver sinusoidal endothelial cell death in a Bim- and Bid-dependent manner. Cell Death Dis 2012; 3: e447.

49. Antico Arciuch VG, Russo MA, Dima M, Kang KS, Dasrath F, Liao XH et al. Thyrocytespecific inactivation of p53 and Pten results in anaplastic thyroid carcinomas faithfully recapitulating human tumors. Oncotarget 2011; 2: 1109-1126.

50. Charles RP, lezza G, Amendola E, Dankort D, McMahon M. Mutationally activated BRAF(V600E) elicits papillary thyroid cancer in the adult mouse. Cancer Res 2011; 71: 3863-3871.

(c) (i) $(\Theta)$ Cell Death and Disease is an open-access journal published by Nature Publishing Group. This work is licensed under a Creative Commons Attribution-NonCommercialNoDerivs 3.0 Unported License. To view a copy of this license, visit http://creativecommons.org/licenses/by-nc-nd/3.0/

\section{Supplementary Information accompanies this paper on Cell Death and Disease website (http://www.nature.com/cddis)}

